http://jmscr.igmpublication.org/home/

ISSN (e)-2347-176x ISSN (p) 2455-0450

crossref DOI: https://dx.doi.org/10.18535/jmscr/v7i12.54

Journal Of Medical Science And Clinical Research

IGM Publication

An Official Publication of IGM Publication

\title{
Serum uric acid level and its correlation with HbA1c in type 2 Diabetes Mellitus
}

\author{
Authors \\ Dr Vibha Sushilendu ${ }^{1}$, Dr Narendra Kumar ${ }^{2}$, Dr Rekha Kumari ${ }^{3}$ \\ ${ }^{1}$ Senior Resident, Dept of Biochemistry, IGIMS, Patna \\ ${ }^{2}$ Assist. Prof., Dept of General Medicine, NMCH, Patna \\ ${ }^{3}$ Add. Prof. and HOD, Dept of Biochemistry, IGIMS, Patna
}

\begin{abstract}
Diabetes Mellitus is a chronic disorder that is associated with cardiovascular complications, renal complications and various types of microangiopathies including metabolic syndrome. Haemoglobin AlC (Hbalc) is a measure of glycosylated haemoglobin over the period 3 months due to the usual lifespan of erythrocytes of 120 days and is used to monitor control of blood glucose levels in patients with DM. Serum Uric acid is the final oxidation product of purine metabolism in the circulation. A cross-sectional, observational study was conducted over a period of six months. 50 patients of more than 18 years of age diagnosed with type 2 Diabetes Mellitus were included in the study and 50 age and sex matched healthy controls were taken. In this study a negative correlation between serum uric acid and HbAlc was observed in patients with type 2 Diabetes Mellitus.

Keywords: Diabetes Mellitus, HbAlc, uric acid.
\end{abstract}

\section{Introduction}

Diabetes Mellitus is a chronic disorder that is associated with cardiovascular complications, renal complications and various types of microangiopathies including metabolic syndrome. The International Federation of Diabetes, reported that around 415 million adults around all over the world are suffering from diabetes, and they estimated that the numbers are likely to reach around 642 million by $2040 .^{[1]}$

Haemoglobin A1C (Hba1c) is a measure of glycosylated haemoglobin over the period 3 months due to the usual lifespan of erythrocytes of 120 days and is used to monitor control of blood glucose levels in patients with $\mathrm{DM}^{[2]}$.
Serum Uric acid is the final oxidation product of purine metabolism in the circulation. Elevated serum uric acids levels are associated with increased risk for cardiovascular disease and so the metabolic diseases such as metabolic syndrome and diabetes mellitus ${ }^{[3]}$. Patients with hyperuricemia are significantly more likely to $\mathrm{DM}^{[4]}$. Some study suggests uric acid may be associated with glycometabolic disorders, because of this association between uric acid and glucose metabolic ${ }^{[5]}$. However, there is not a linear association between uric acid and blood glucose levels. Hyperuricemia in patients with diabetes mellitus type 2 associated with increased risk for diabetic nephropathy ${ }^{[6]}$. 
Recent studies have demonstrated that serum uric acid levels are higher in subjects with prediabetes and early type 2 diabetes than in healthy controls $^{[7,8]}$. Hyperuricemia has been also added to the set of metabolic abnormalities associated with insulin resistance or hyperinsulinemia in metabolic syndrome. ${ }^{4-6}$

\section{Material and Methods}

A cross-sectional, observational study was conducted in the Department of Biochemistry, IGIMS, Patna, over a period of six months. 50 patients of more than 18 years of age diagnosed with type 2 Diabetes Mellitus were included in the study and 50 age and sex matched healthy controls were taken. Patients with chronic liver or kidney diseases, cancer, or taking diuretics were excluded from the study.

Statistical analysis was done using MS Excel software. $p$ value $<0.05$ was taken as statistically significant.

\section{Result}

There were 40 males and 10 females in the control group with the mean age of $42.5 \pm 13.5$ years. The mean age of cases were $54.4 \pm 11.3$ years. The mean HbA1c of cases and control were 7.2 $\pm 1.20 \%$ and $5.5 \pm 0.4 \%$ respectively. Uric acid level was found to be $7.4 \pm 2.4 \mathrm{mg} / \mathrm{dl}$ in cases with the creatinine level of $1.20 \pm 0.41 \mathrm{mg} / \mathrm{dl}$. The fasting blood glucose level in cases was $138.7 \pm$ $47.4 \mathrm{mg} / \mathrm{dl}$.

Table 1: Gender distribution of cases and control

\begin{tabular}{|l|c|c|}
\hline & cases & control \\
\hline male & 35 & 40 \\
\hline female & 15 & 10 \\
\hline Age (yrs) & $54.4 \pm 11.3$ & $42.5 \pm 13.5$ \\
\hline
\end{tabular}

Table 2: Level of different parameters in cases and control

\begin{tabular}{|l|c|c|c|}
\hline \multicolumn{1}{|c|}{ parameter } & cases & control & $\mathrm{p}$ value \\
\hline HbA1c & $7.2 \pm 1.2$ & $5.5 \pm 0.4$ & $<0.01$ \\
\hline Uric acid $(\mathrm{mg} / \mathrm{dl})$ & $7.4 \pm 2.4$ & $6.3 \pm 1.9$ & 0.01 \\
\hline Creat. $(\mathrm{mg} / \mathrm{dl})$ & $1.2 \pm 0.4$ & $0.9 \pm 0.2$ & $<0.01$ \\
\hline BUN $(\mathrm{mg} / \mathrm{dl})$ & $28.6 \pm 10.8$ & $19.9 \pm 8.5$ & $<0.01$ \\
\hline FBS $(\mathrm{mg} / \mathrm{dl})$ & $138.7 \pm 47.4$ & $96.5 \pm 38.3$ & $<0.01$ \\
\hline
\end{tabular}

\section{Discussion}

Over the years, the association between uric acid levels and glucose metabolism has been a hot research topic. A growing number of studies have indicated that there is a bell fit between uric acids and glucose concentrations. Many previous studies have linked uric acid to type 2 diabetes mellitus, but studies linking uric acids to HbA1c are scarce. Some studies have observed an increase in Uric acid levels in type 2 diabetes mellitus and our study found that there was no association between $\mathrm{HbA} 1 \mathrm{c}$ and uric acid level in the subjects.

In this study a negative correlation between serum uric acid and HbA1c was observed in patients with type 2 Diabetes Mellitus. Similar findings were seen in the research by Yuliang Cui et al. that is an inverse correlation between uric acid and HbA1c. Some studies have found that serum uric acid levels are inversely correlated with blood glucose concentration in type 2 diabetes mellitus patients. However Sirsath et al, found a positive correlation of uric acid levels with $\mathrm{HbAlc}$ in diabetic subjects. Rusdiana et al, found no significant association between Hbalc and uric acid levels among the study subjects.

High insulin levels may be important factor affecting the correlation between the uric acid and HbA1c, the same with Fengjiang Wei et al. They found that serum uric acid level is inversely associated with $\mathrm{HbA1c}$ in Type 2 Diabetes Mellitus patients. Walid G Babkir et al showed that in patients with type 2 diabetes mellitus serum uric acid level has an adverse effect on 
glycemic control, but the research by V. Pavithra etc. has strongly established an association between uric acid and $\mathrm{HbA} 1 \mathrm{c}$ thereby linking uric acid, the end product of purine metabolism to DM.

\section{Conclusion}

Serum Uric Acid level is inversely associated with HbA1c in patients with type 2 Diabetes Mellitus , but positively correlated with HbA1c in normal subjects. Further studies with larger sample size is required.

\section{Conflict of Interest: None}

\section{References}

1. Akhtar SN, Dhillon P. Prevalence of diagnosed diabetes and associated risk factors: Evidence from the large-scale surveys in India. Journal of Social Health and Diabetes 2017;1;5:28.

2. Cui Y, Bu H, Ma X, Zhao S, Li X, Lu S. The relation between serum uric acid and $\mathrm{HbA1c}$ is dependent upon hyperinsulinemia in patients with newly diagnosed type 2 diabetes mellitus. Journal of diabetes research. 2016; 2016.

3. Lv Q, Meng XF, He FF, Chen S, Su H, Xiong J, Gao P, Tian XJ, Liu JS, Zhu ZH, Huang K. High serum uric acid and increased risk of type 2 diabetes: a systemic review and meta-analysis of prospective cohort studies. PloS one. 2013; 8(2):e56864.

https://doi.org/10.1371/journal.pone.00568 64 PMid:23437258 PMCid:PMC3577701

4. Qiu Q, Gong Y, Liu X, et al. Serum uric acid and impaired glucose tolerance: The Cardiometabolic Risk in Chinese (CRC) Study, Cell Biochemistry and Biophysics. 2015; 73:1:155-162. https://doi.org/10.1007/s12013-015-05975 PMid:25707501

5. Rathmann W, Hauner H, Dannehl K, Gries FA. Association of elevated serum uric acid with coronary heart disease in diabetes mellitus. Diabetes Metabolisme. 1993; 19:1-2:159-166.

6. Hovind P, Rossing P, Johnson RJ, Parving $\mathrm{HH}$. Serum uric acid as a new player in the development of diabetic nephropathy. Journal of Renal Nutrition. 2011; 21(1):124-7.

7. Alberti KG, Zimmet P, Shaw J. Metabolic syndrome - a new world-wide definition. A consensus statement from the international diabetes federation. Diabetic medicine 2006; 23:469-80.

8. Poulsen P, Kyvik KO, Vaag A. Heritability of type 2 (non-insulin dependent) diabetes mellitus and abnormal glucose tolerance-a population-based twin study. Diabetologia 1999; 42:125127.

9. Rich SS. Mapping genes in diabetes: genetic epidemiological perspective. Diabetes 1990;39:1315- 1319.

10. Cook JT, Shields DC, Page RC, et al. Segregation analysis of NIDDM in Caucasian families, Diabetologia 1994; 37:1231-1240.

11. Perley MJ, Kipnis DM. Plasma insulin responses to oral and intravenous glucose: studies in normal and diabetic subjects. $\mathrm{J}$ Clin Invest 1967; 46:1954- 1962.

12. Wei F, Chang B, Yang X, Wang Y, Chen L, Li WD. Serum uric acid levels were dynamically coupled with hemoglobin A1c in the development of type 2 diabetes. Scientific reports. 2016; 6:28549. https://doi.org/10.1038/srep28549 PMid:27328642 PMCid:PMC4916504

13. Babikr WG, Elhussein AB, Abdelraheem A, Magzoub A, Mohamed H, Alasmary M. The Correlation of Uric Acid Levels with Glycemic Control in Type II Diabetic Patients. Biomedical and Pharmacology Journal. 2016; 9(3):1005-8.

14. Rusdiana, Sri Suryani Widjaja, Muhammad Syahputra, Maya Savira: Association between Haemoglobin A1c 
and Uric Acid Levels among Patients with Diabetes Mellitus Type 2 at a Primary Health Care Clinic in North Sumatera, Indonesia :Macedonian Journal of Medical Sciences. 2018 Sep 25; 6(9):1633-1635

15. Akshay Shirsath, Virendra C Patil, Makarand Mane, Shilpa Patil: A Study of Serum Uric Acid Levels in Type 2 Diabetes Mellitus Subjects: A Cross Sectional Study: International Journal of Contemporary Medical Research :January 2019 : Volume 6, Issue 1 ,pg A21-24. 